\title{
Mitigating the Nursing Shortage Phenomenon via Improved Retention
}

\author{
J Dirk Nelson $^{1^{*}}$ and Helen Reyes ${ }^{2}$ \\ ${ }^{1}$ Ph.D, College of Nursing and Health Sciences, West Texas A\&M University. \\ ${ }^{2}$ Ed.D, College of Nursing and Health Sciences, West Texas A\&M University.
}

Received: April 20, 2018; Accepted: April 23, 2018; Published: April 25, 2018

*Corresponding author: J Dirk Nelson, College of Nursing and Health Sciences, West Texas A\&M University; E-mail:- jdnelson@wtamu.edu

\section{Editorial}

Over the course of the last several years, the United States has seen a declining number of nurses. The seriousness of this phenomenon is likely to be exacerbated as additional strains are placed on healthcare due to the aging of the nation's population (The Campaign for Nursing's Future, Johnson \& Johnson). Even though registered nurses represent the largest group of healthcare professionals, vacancies for RNs continue to rise. Moreover, it is estimated by 2026, the United States will need some 438,100 additional nurses (United States Department of Labor).

As per the American Association of Colleges of Nursing, the consequences of a lack of adequate nurses is substantial and include:

- Increased patient load for RNs in pediatric hospitals increases the likelihood of readmission.

- Greater workloads for nurses due to high patient turnover will increase mortality rates.

- Lower patient-nurse ratio significantly decreases patient mortality.

- Increased nurse staffing reduce duration of patient stays.

How we arrived at this point of having too few nurses is certainly multifactorial. First, our nation is aging. By 2030, all of the Baby Boomers will be over the age of 65. In 2050 the number of people over 65, will be more than double what it was in 2008 (88.5 million vs. 38.7 million). During this same period of time (2008 to 2050), the number of people at least 85 years of age will increase over $300 \%$ (5.4 million vs. 19 million). With the higher number of older adults, there will be a greater need for geriatric care, which naturally includes treatment of chronic diseases and their respective comorbidities.

Concomitantly, nurses are aging. At present, some 55\% of the $\mathrm{RN}$ workforce is over 50 years of age; and more than 1 million RNs will reach retirement during the upcoming 10 to 15 years.
Certainly another factor contributing to the RN shortage is nursing schools' challenges to increase enrollments due to inadequate number of qualified, skilled, and dedicated faculty. Annually, over 75,000 qualified applicants to nursing schools (baccalaureate and APRN) are turned away due to lack of faculty, clinical sites, clinical preceptors, and financial constraints. Additionally, during a typical academic year, there may be over 1200 full-time nursing faculty vacancies which go unfilled due to:

- Low salaries for nursing educators vs. clinicians

- Lack of nurses with advanced degrees

- Late point in career for changing to an academic role

- Pending retirement of current nursing educators

Lastly, one contributing faculty to the nursing shortage is turnover rates in healthcare facilities. Data indicate that some 13 to $16 \%$ of all nurses employed in hospitals leave their positions within one year, and more than $1 / 3$ claim they felt ready to change jobs. The key reason why nurses leave the profession include:

- Poor management

- Lack of opportunity

- Disillusionment with nursing

- Overworked, underpaid

The question of why nurses leave the profession is very complex and it is (or certainly should be) of great interest to healthcare professionals as well as administrators; to nursing educators and their students; and to our nation's citizenry. Attracting and retaining nurses therefore, is key to our health, productivity, and financial security. This nursing attrition phenomenon is not only a problem for the public; it may well be considered a failure of a healthcare facility to achieve its purpose. Therefore, here are three strategies hospitals can take to better retain nurses. 


\section{No More Passing the Sting}

According to Gillespie, et.al. (2017), bullying (commonly referred to as "nurses eating their young") continues to exist in the profession. Research shows that the incidence of bullying ranges from $30 \%$ of RNs reporting such, to as high as $72 \%$ among newly licensed nurses. Succinctly, this phenomenon must not be tolerated and needs to be stopped immediately. This behavior has no place in society, and certainly no place in a healthcare facility. "Passing the sting" is not only from nurse to nurse, but possibly from physicians, supervisors, and from other hospital staff as well. In an organization (hospital), passing the sting is a phenomenon which can easily divert energy away from the institution's mission. Nurse Managers are the frontline; they are in the best position to understand bullying (unfortunately, they may have experienced such). They are in the best position to sense when bullying is about to occur (or has occurred). Nurse Managers are in the best position to create a set of rules which prevents bullying. And, they are in the best position to demonstrate dignity to and respect for their new nurse colleagues. New nurses should have quality interactions with all members of the healthcare team. Provide opportunities for new nurses to play a role in an important initiative or project. Interactions which include affirmation as well as correction when needed are to be done in an environment of courtesy, dignity and respect. Nurses have been identified by the public for nearly two decades as being the most respected professionals in our nation. The nursing profession and healthcare colleagues should show this same level of respect and admiration to their new colleagues. Valuing nurses should not be simply "lip service." It must be consistently practiced by everyone on the healthcare team - from nursing education, to clinical, to career.

\section{Together, We Can Do This!}

For any institution to become truly great, and truly make a difference, there must be a willingness to work together. It is well recognized that no one ever achieves alone what otherwise could have been accomplished when partnering with others. While not exclusive, currently, it is too common for nursing education and hospitals to be two separate entities in the progress from nursing student to nursing career. Certainly, hospitals play an important role in offering clinical placements for nursing students. However, there needs to be more examples of nursing education programs and hospitals working in symbiosis. Consider the following possibilities:

- Joint faculty, clinical appointments. A hospital assumes 50\% of the expense, and a nursing program assumes the other $50 \%$ to hire qualified individuals to serve clinically in the hospital and simultaneously as an educator. This helps address the nursing shortage by allowing more qualified students to be admitted.
- Encourage and incentivize baccalaureate nurses to pursue graduate degrees in nursing. This improves patient care; and increases the local pool of qualified candidates for nursing faculty appointments.

- Offer grants to nursing faculty for research looking at improving the quality of nursing education. A relatively small investment in the form of a grant may yield substantive dividends to the hospital.

- Create a competitive scholarship for local nursing students. Recipients may have a required commitment to work at the hospital for a period of time following licensing.

- Develop a high fidelity simulation center. This could be used by current hospital employees for continuing education, but by nursing education programs as well; some of which may not have the resources to fund simulation education on their own.

\section{Small Things Can Make a Big Difference}

It has been established for decades that money is not the main reason individuals seek a career. While compensation and benefits are important, salary is consistently ranked below several other reasons people go to work, and remain committed to their career. Nurses matter; nurses' contributions to the healthcare facility and to our nation are vital...are they told that? Do nurses sense they matter that much? Much of life is lived in the small gestures made from one person to another. While high tech is ubiquitous, never forget the impact of a hand-written note, or a few moments of "face time." While talent, intelligence and education are wonderful - these (either collectively or individually) do not ensure success. More is required; the awareness to understand what other people want and need - and the willingness to give it to them. Interesting; isn't this what nurses do for a living? Do for your RNs, what they do for others, and your nurses will be much more likely to stay.

\section{References}

1. American Association of Colleges of Nursing; The Voice of Academic Nursing. Fact Sheet: Nursing Shortage.

2. Gordon L. Gillespie, Paula L. Grubb, Kathryn Brown, Maura C. Boesch, Deborah Ulrich. "Nurses Eat Their Young": A Novel Bullying Educational Program for Student Nurses. J Nurs Educ Pract. 2017;7(7):11-21. Doi:10.5430/jnep.v7n7P11

3. Nursing Shortage Effect on the Health Care Industry: Current Trends, Future Growth. 2016;

4. The Campaign for Nursing's Future. National Nursing Shortage. Johnson\&Johnson.

5. The Nursing Shortage and How It Will Impact Patient Care. 2017; 